\title{
A CENTRALIZAÇÃO DE ESTOQUES DENTRO DE UMA INSTITUIÇÃO DE ENSINO NA CONTENÇÃO DE CUSTOS
}

Vagner Alexandre da Silva Coutinho, Claudio José Donato, Irene Caires da Silva

Universidade do Oeste Paulista - UNOESTE, MBA em Logística, Presidente Prudente, SP. E-mail: vcoutinho02@gmail.com; claudio.donato@hotmail.com; irene@unoeste.br

\section{RESUMO}

O objetivo deste estudo consiste em mostrar o quanto é importante à centralização de estoques dentro de uma instituição de ensino, visando agilidade, administração eficiente, eficaz e com isso reduzindo o desperdício de materiais. A metodologia adotada para realizar este estudo foi à pesquisa bibliográfica. Conclui-se que o almoxarifado ou centro de distribuição é o local responsável pelo recebimento de produto, armazenagem, expedição e distribuição dos materiais e é imprescindível que este departamento seja único para que todos os processos sejam feitos em um único lugar, visando controle administração logística e contenção de custos.

Palavras-chaves: Almoxarife. Logística. Custos. Movimentação. Estoque.

\section{THE CENTRALIZATION OF STOCKS WITHIN AN INSTITUTION OF TEACHING IN COST CONTENT}

\begin{abstract}
The objective of this study is to show how important it is to centralize inventories within a teaching institution, aiming for agility, efficient administration, and thus reducing material waste. The methodology adopted to carry out this study was the bibliographic research. It is concluded that the warehouse or distribution center is the place responsible for the receipt of product, storage, dispatch and distribution of materials, it is essential that this department is unique so that all the processes are done in a single place, aiming at the control of logistics and Containment of costs.
\end{abstract}

Keywords: Warehouse. Logistics. Distribution. Costs. Stock.

\section{INTRODUÇÃO}

O almoxarifado é de vital importância para a organização, pois consiste em armazenar todos os produtos e bens de forma responsável e organizada e estes sejam disponibilizados com agilidade sempre que solicitados. Hoje dentro desta rede de ensino existem cerca de 34 almoxarifados. O que seria de suma importância à unificação desses departamentos para que as compras de materiais se concentrassem em um único local, visando maior poder de compra e barganha e consequentemente redução de custos. Esses almoxarifes tem o poder de pedido de compra, oque acontece, que muitas vezes, é que acabam pedindo o mesmo produto com quantidades diferentes, o que ocasiona um grande volume de notas fiscais com os mesmos produtos.

A unificação dos almoxarifados tem como essência a economia de tempo e redução com os custos, sendo assim possibilitar que todas as compras sejam feitas de uma forma integrada e observando que quanto maior o volume de compra maior o poder de negociação. Essa unificação facilitaria a logística de vários setores, como departamento de transporte, compras, financeiro e a facilitação dos usuários que utilizam o departamento de almoxarifado para requisitar seus 
materiais, ou seja, a busca pelo produto seria em apenas um lugar e não nos diversos almoxarifes que essa instituição possui.

Sendo assim, a grande quantidade de almoxarifes, contribui com excesso e duplicidade de pedidos, gerando transtorno entre as partes o que acarreta com o aumento dos custos operacionais da empresa.

O presente estudo tem como objetivo principal evidenciar o quanto é importante á centralização de estoques dentro de uma instituição de ensino, visando agilidade, administração eficiente, eficaz e com isso reduzindo o desperdício de materiais

\section{METODOLOGIA}

O estudo em questão tem como metodologia uma pesquisa de natureza tipo bibliográfico, buscando informações em doutrinas, artigos, periódicos, meios eletrônicos, entre outros.

A metodologia empregada no estudo abrange a especificação do delineamento da pesquisa bibliográfica e digital; conceito e definição de almoxarifes; procedimentos utilizados para viabilizar a centralização de estoque e com isso ter redução de custos dentro de uma instituição de ensino. A prática do vigente estudo foi composta por busca da literatura especializada, disponível nas bibliotecas, dissertações pertinentes, pesquisa exploratórias, disponíveis no meio eletrônico e em formato físico para maior embasamento teórico.

Por fim, essa modalidade de pesquisa é realizada em material anteriormente publicado, como artigos e livros, e sua principal vantagem é "permitir ao investigador a cobertura de uma gama de fenômenos muito mais ampla do que aquela que poderia pesquisar diretamente" (GIL, 2002, p. 44).

\section{RESULTADOS}

Levando em consideração que essa instituição de ensino é de grande porte com um grande número de alunos e instalações prediais, à também um número elevado de almoxarifados dentro dessa empresa, o que acaba gerando transtorno por parte dos usuários, que ao requisitarem seus produtos, na maioria das vezes ficam em dúvida em qual almoxarifado pesquisar.

Nesse sentido, a unificação dos almoxarifados facilita o desenvolvimento da contenção de custos, bem como centralizar os procedimentos de almoxarife em um único setor, visando agilidade, e uma gestão eficiente capaz de redução dos custos e desperdício de materiais facilitando a logística operacional.

Dessa forma a capacidade da organização em seu gerenciamento está em primeiro lugar sendo um diferencial dos seus concorrentes, e em segundo lugar, operando com menor custo possível gerando maior lucratividade.

Sendo assim esse diferencial é a preocupação de toda da organização, com as novidades que o mercado oferece, buscando uma vantagem competitiva e tornando seus serviços, com diferenciação e potencialidade. Quando esse diferencial é alcançado, os níveis desejados de qualidade e de serviços prestados, sempre estarão ao menor custo possível (CHRISTOPHER, 2007). Assim falando em resultados, vale ressaltar conforme Moura $(1998$, p. 9) as cinco gerações de movimentações de materiais, que vão desde os tempos antigos aos modernos:

Primeira geração: homens (animais) movimentando materiais com seu próprio esforço. Segunda geração: homens movendo (direção) materiais utilizando equipamento para reduzir o esforço: Terceira geração: homens movimentando (controles) materiais automaticamente entre processos. Quarta geração: materiais em movimento automático entre processos automáticos. Quinta geração: inteligente, a melhor movimentação e materiais é o de mínimo movimento de estocagem. 
Nesse sentido, vimos que a movimentação dos produtos evoluiu, e que o departamento de almoxarifados em qualquer organização é um excelente instrumento de gestão, que vai desde ao pedido de compras, recebimento, conferencia, entradas de notas, estocagem, expedição e distribuição dos produtos de forma organizada e planejada, objetivando a contenção de custos, das ferramentas utilizadas, que vão desde transporte logístico e mão de obra. Dessa forma as vantagens de centralização de estoque consta que a logística é uma das operações mais complexas das empresas, pois é responsável pela movimentação, estocagem, processamento de pedidos e entregas. A cadeia de suprimentos lida diretamente com a satisfação do cliente, competitividade e rentabilidade das empresas. Os fatores-chaves da cadeia se estruturam para atingir o nível de satisfação do cliente com menor custo possível. Na logística, existem ainda os canais de distribuição, responsáveis por encaminhar as mercadorias aos clientes nas quantidades corretas. A estocagem centralizada pode aumentar a eficiência na proporção em que reduz os custos (SILVIA; SOUZA, 2014).

A centralização de estoques diminui os custos para a empresa, reduzindo assim o processamento dos pedidos, proporcionando uma alta economia de escala, fator importante para a estratégia da empresa, pois os descontos concedidos em compras ocorrem através de negociações em grande quantidade, e assim oferecendo melhor visualização dos estoques. A centralização pode reduzir os custos operacionais, podendo contar com um quadro menor de funcionários, ao contrário do que ocorreria se tivesse mais de um centro de distribuição ou almoxarifado,quando os gastos com estocagem, manutenção e movimentação seriam bem maiores. Outro fator da centralização é a redução do estoque, já que no centro de distribuição contará com um estoque mínimo. Se a empresa possuir vários almoxarifes necessitaria de uma quantidade maior de estoque mínimo em suas filiais (SILVIA; SOUZA, 2014).

Assim a centralização como estratégia na logística é uma fronteira na busca de vantagem competitiva real. Contudo a centralização dos estoques como estratégia, através dos Centros de Distribuição permite a exploração de novos mercados e consequentemente conquistar uma posição única e sustentável, garantindo a participação em um mercado cada vez mais concorrido e exigente (MATHIAS, 2015).

E por fim, esse departamento de almoxarifado obtendo essa unificação e centralização facilitará o processo de gestão na tomada de decisão, sendo um diferencial no mercado.

\section{DISCUSSÃO}

O almoxarifado é lugar responsável pelo recebimento, armazenagem, guarda distribuição, validade, controle de entradas e saídas de mercadorias destinadas os setores de qualquer organização. A boa ordenação desse departamento, deve-se ter em conta, o cálculo das quantidades de produtos que se deve possuir em estoque é imprescindível e significa para a empresa um bom resultado de economia, em redução de custos em materiais e principalmente nas atividades de logística de distribuição, objetivando assim um bom atendimento, rápido e eficiente aos setores e departamentos da instituição (BARBOSA, 1985). 


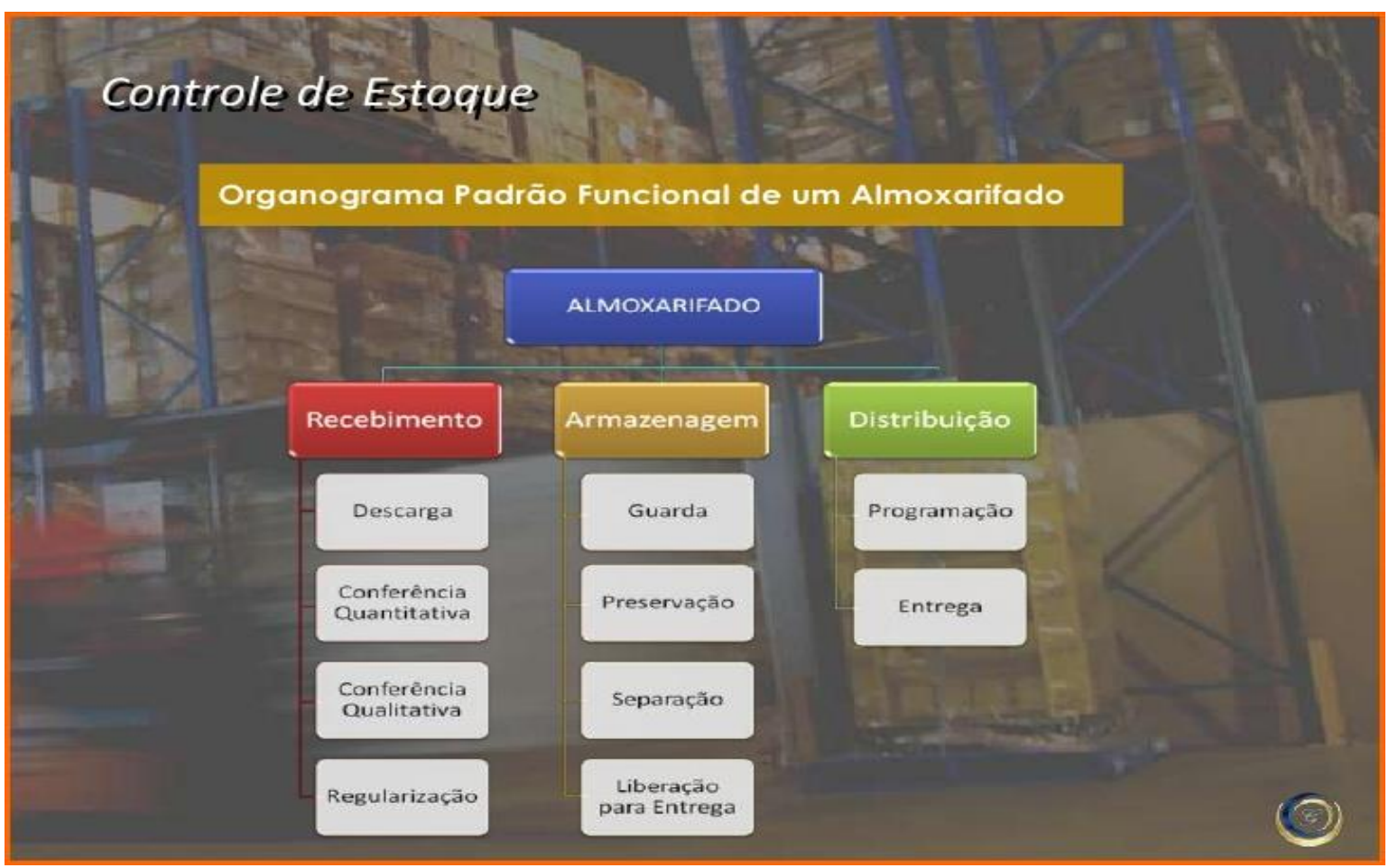

Fonte: https://pt.slideshare.net/blumauricio/almoxarifado

A missão do almoxarifado qualquer que seja a classe, é dar apoio e dessa forma servir de intermediário, dando suporte, armazenando de forma correta e responsável os produtos da organização. Assim são constituídos, como estabelecimentos que guardam os valores do patrimônio da empresa e quando necessário distribuem aos departamentos (ARAÚJO, 1985).

O almoxarifado central ou centro de distribuição deve obedecer quais materiais vão ser estocados, para serem distribuídos dentro da sua instalação e ser acomodados da melhor forma possível, visando segurança, eficiência e tanto na sua acomodação dos materiais, quanto na distribuição dos mesmos aos setores. (Barbosa, 1985).

Para melhor organização o almoxarifado ou centro de distribuição deverá conter lugares específicos para cada material, ou seja, lugar adequado para itens de limpeza, escritórios, gêneros alimentícios, laboratoriais, construção civil, manutenção, serviços e informática, para que todas as atividades executadas sejam desempenhadas, de forma segura e eficiente, sempre visando o bom atendimento e é claro, redução de custos (BARBOSA, 1985).

Diante da modernidade, hoje os grandes centros de distribuição estão acondicionados com código de barra, uma importante ferramenta no controle dos produtos para abastecimento dos setores de qualquer organização, dando melhor parâmetro de custo de aquisição, preço médio, origem, destino, saldo em valor e quantidade (BARBOSA, 1985).

A organização dos serviços de cadastro de produto deve seguir um padrão especializado, para que as compras sejam feitas da melhor forma possível, sem erros ou equívocos. Sendo assim, o almoxarife tem a função de manter uma empresa, sempre abastecidas de seus bens de consumo e serviço, ou seja, fornecer de forma contínua e sistêmica e sem interrupção materiais e matériasprimas para as diversas unidades produtivas e administrativas da organização.

Sua organização depende das entradas e saídas de produtos e para que se torne suficiente às necessidades da organização. Sua função básica e abastecer e alimentar os todos os setores da organização, com produtos nas quantidades necessárias, no tempo certo ao menor custo possível. Assim evitando grandes pedidos de materiais, que venham exceder o consumo e desta forma imobilizando capital da organização (ARAÚJO, 1985). 
As funções básicas do almoxarifado estão em solicitação e pedido de material ao departamento de compras, receber as mercadorias e ter o conhecimento adequado sobre o material em questão. Sobre sua responsabilidade está à guarda e estocagem, mantendo o estoque organizado permitindo a redução de custos por meio do controle de estoque e a distribuição dos produtos em tempo hábil.

Outro fator de sua responsabilidade é a distribuição, nada mais é que fornecer aos seus usuários, os materiais com eficiência, controle do tempo e é claro agilidade. Esses informes são um verdadeiro freio contra o desperdício e a irresponsabilidade. Um almoxarifado organizado reflete em boa padronização, que resultará em resultados compensadores em todos os sentidos físicos e econômicos, facilitando as operações administrativas, relacionados com uma boa previsão e controle, resultando pela redução de itens (ARAÚJO, 1985).

\section{CONCLUSÃO}

O presente estudo abordou o quanto é importante á centralização de estoques dentro de uma instituição de ensino, visando agilidade, administração eficiente, eficaz e com isso reduzindo o desperdício de materiais.

$\mathrm{Na}$ seqüência, verificou importância à unificação desses departamentos para que as compras de materiais se concentrassem em um único local, visando melhor o gerenciamento dos custos e poder de investimento em compra.

Foi enriquecedora a pesquisa para ter conhecimento que a instituição em questão, possui um grande número de almoxarifes, o que ocasiona um grande número de pedidos de compra e às vezes coincidindo o mesmo material. Tendo ainda o problema da não padronização de sistemas, pois existem almoxarifados nesta instituição, que ainda utilizam pedidos de material em forma de talão de requisição, o que acarreta em tempos maiores, na execução dos trabalhos de saídas de produtos.

Constatou que a sugestão de padronizar um almoxarife central, ou centro de distribuição central, para fazer todos os pedidos de compra, recebimento, estocagem e distribuição, a esses outros almoxarifes que serão na realidade subalmoxarifados, onde farão a distribuição dos produtos aos setores competentes.

Por fim, a centralização de estoques visa, redução de custos, maior controle dos materiais e produtos destinados a essa instituição, bem como, agilizar os processos admirativos e operacionais.

\section{REFERÊNCIAS BIBLIOGRÁFICAS}

ALMOXARIFADO. 30 de jul de $2012 . \quad$ Disponível em:<https://pt.slideshare.net/blumauricio/almoxarifado>. Acesso em: 04 abr. 2015.

ARAÚJO, J.S. Almoxarifados: admistração e organização. 9. ed. São Paulo: Atlas, 1986.

BARBOSA, E. Almoxarifado e bens patrimoiais a nível municipal. 2. ed. São Paulo: Fundação Prefeito Faria Lima-Cepam, 1985.

CHRISTOPHER, M. Logística e gerenciamento da cadeia de suprimentos: criando redes que agregam valor. 2. ed. São Paulo: Thomson Learning, 2007.

GIL, A. C. Como elaborar projetos de pesquisa. 4.ed. São Paulo: Atlas, 2002. 
MATHIAS. R. V.; RODRIGUEZ, C.M.T.; GONÇALVES, M.B. Centralização e descentralização como estratégia logística. 2015.2017 Disponível <file:///C:/Users/Sony/Downloads/01443047374\%20(6).pdf>. Acesso em: 08 maio 2017

MOURA, A. R. Sistemas e técnicas de movimentação e armazenagem de materiais. 4. ed. São Paulo: IMAM, 1998. (Série manual de logística)

SANTOS. A. Centros de distribuição como vantagem competitiva. Disponível em: <http://www.pgsskroton.com.br/seer/index.php/rcger/article/download/2710/2574>. Acesso em: 08 maio 2017.

SILVIA, L. R.; SOUZA, T. C. Vantagens de centralização de estoque em uma empresa de varejo na cidade de lins. Lins, 2014. 